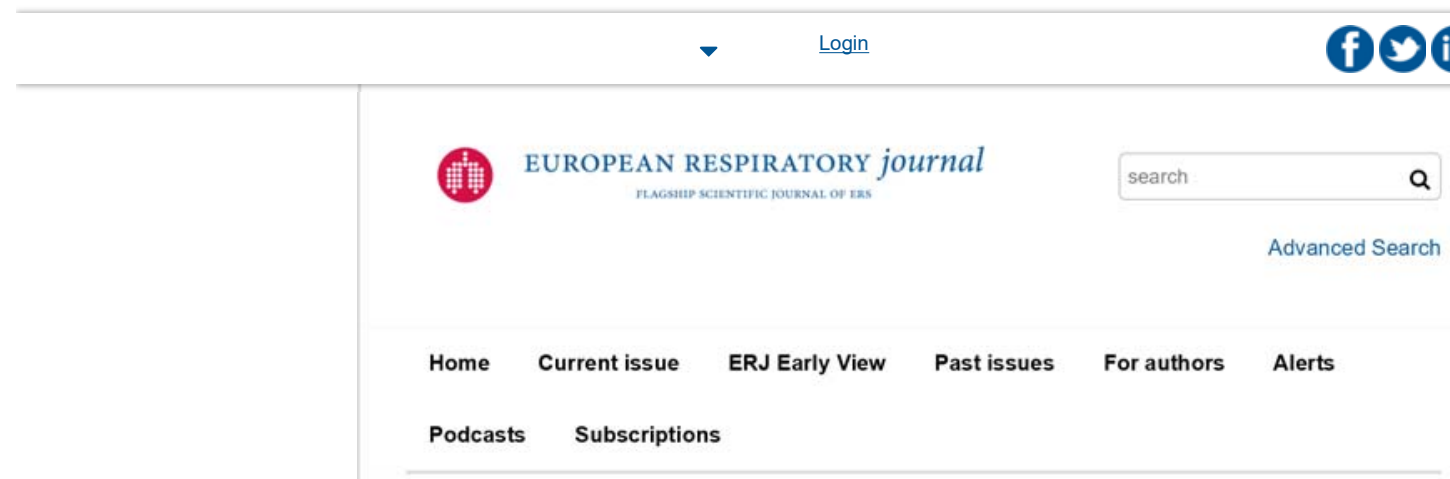

\title{
(4)
}

\section{Impact of leaks on respiratory effort during sleep in patients treated by Non Invasive Ventilation}

Olivier Contal, Jean-Christian Borel, Nathalie Arnol, Kébir Sabil, Jean-Louis Pépin, Jean-Paul Janssens European Respiratory .Journal 2019 54: PA3692; DOI: 10.1183/13993003.congress-2019. PA3692

$$
\text { Article Info \& Metrics }
$$

\section{Abstract}

Background: During NIV, unintentional leaks are usually considered as a factor increasing respiratory effort but this assumption remains poorly documented for pressure support NIV devices with a high capacity of leak compensation.

Objectives: to assess the impact of different level of induced leaks on (i) respiratory effort and (ii) pressure supplied by the NIV device during sleep.

Methods: 10 stable patients with Obesity Hypoventilation Syndrome (OHS) (6males, age: $56 \pm 12$, BMI: $35 \pm 5 \mathrm{~kg} / \mathrm{m} 2$ ) treated with nocturnal NIV were studied by type-1 polysomnography (PSG) including an oesophageal pressure (POES) measurement. Two levels of unintentional leaks (24 and 60L/min; respectively low (LL) and high leaks (HL)) were randomly induced in the circuit using a computercontrolled solenoid valve during non-REM sleep. Every period of induced leaks lasted 5 minutes. Pressure supplied by NIV (PNIV) and areas under the curve of POES were calculated for each level of leaks and reported as relative change from baseline (no leaks). A generalized linear mixed model was used to estimate the variations of POES and PNIV according to the level of leaks.

Results: 8 patients had exploitable experiments. 2076 respiratory cycles with leaks were analysed. $\mathrm{HL}$ and $\mathrm{LL}$ did not induce significant modifications of POES compared to no leaks (Med[Q1;Q3]) $(-4.3[-26.2 ; 17.0] v s-$ $2.4[-32.4 ; 25.4] \%$ of Poes respectively for LLvsHL $p=0.42$ ). In contrast, PNIV increased significantly during leaks $(2.3[1.6 ; 3.4]$ vs $5.8[4.1 ; 8.7] \%$ of PNIV respectively for LLvsHL; $p$ p <0.001]

Conclusion: Unintentional leaks do not systematically increase inspiratory effort in nocturnal NIV. This may be
Vol 54 Issue suppl 63 Table of
Contents

Table of Contents

Index by author

A Email
$\begin{aligned} & \text { Citation } \\ & \text { Tools } \\ & \text { Permissions }\end{aligned}$
Jump To Share
Article
Info \& Metrics


explained by an overcompensation of the ventilator

when leaks occur.

More in this TOC Section

Mechanical ventilation - interactions and complications Adults

Late Breaking Abstract - Cost-

effectiveness of outpatient (OP) vs.

inpatient (IP) setup of home non-

nvasive ventilation (NIV) in obesity

(N)

Footnotes

Cite this article as: European Respiratory Journal 2019;

54: Suppl. 63, PA3692.

This is an ERS International Congress abstract. No fulltext version is available. Further material to accompany

this abstract may be available at www.ers-education.org (ERS member access only).

Copyright (Cthe authors 2019

Randomised Clinical Trial

Screening for Sleep-Disordere

Breathing in Patients Awaiting

Bariatric Surgery: Comparison

between two European Centres

Nasal high-flow in acute

hypercapnic exacerbation of COPD

Show more Nonitrvasive vertiliatory support

Related Articles

\section{We recommend}

Observational study of sleeprelated breathing disorders

and preventive non-invasive ventilation in cystic fibrosis

Giuseppe Fabio Parisi et al.. European Respiratory

Journal, 2019

Physiologic Effects of

Noninvasive Ventilation

PracticeUpdate, 2019

Multidisciplinary Care

Allowing Uneventful Vaginal

Delivery in a Woman With

Pompe Disease

Pulse transit time allows a

reliable non-invasive

measurement of respiratory

effort under non-invasive

ventilation

PracticeUpdate, 2016

Future Noninvasive

Ventilation Strategies in

Neonates

Kimberly S. Firestone et al.

Olivier Contal et al.. European

Respiratory Journal, 2012

Neoreviews, 2017

Sleep quality during home

noninvasive ventilation (NIV).

Jasmine Sutter et al.

European Respiratory

Journal, 2018

Is positive expiratory pressure

(PEEP) during noninvasive

ventilation (NIV) useful in

patients with amyotrophic

lateral sclerosis (ALS)?

Central sleep apnea device

increases mortality in patients

with $\mathrm{HF}$

Healio

Initiation of Noninvasive

Ventilation for Acute

Respiratory Failure in a

Pediatric Intermediate Care

Grazia Crescimanno et al.

Alla Smith et al., Hosp

Pediatr, 2019

European Respiratory

Journal, 2014

Increasing CPAP (Continuous

Positive Airway Pressure)

leads to increasing trans-

pulmonary pressure with

increased activity of the

abdominal wall muscles to aid

Expiration

Michael Apps et al., European

Respiratory Journal, 2019

Powered by TREND MD

I consent to the use of Google Analytics and related cookies across the

TrendMD network (widget, website, blog). Leam more

Q Previous

^ Back to top

Navigate

Home

Current issue

Archive
The European

For authors

Respiratory Society

Society home

myERS

Privacy policy
Instructions for authors

Submit a manuscript

ERS author centre

Contact us 


\begin{tabular}{|c|c|c|c|}
\hline About the ERJ & Accessibility & For readers & $\begin{array}{l}\text { European Respiratory } \\
\text { Society }\end{array}$ \\
\hline \multirow{7}{*}{$\begin{array}{l}\text { Journal information } \\
\text { Editorial board } \\
\text { Reviewers } \\
\text { CME } \\
\text { Press } \\
\text { Permissions and } \\
\text { reprints }\end{array}$} & \multirow[b]{2}{*}{ ERS publications } & Alerts & 442 Glossop Road \\
\hline & & Subjects & Sheffield S10 2PX \\
\hline & \multirow{2}{*}{$\begin{array}{l}\text { European Respiratory } \\
\text { Journal }\end{array}$} & Collections & United Kingdom \\
\hline & & Podcasts & Tel: +44 1142672860 \\
\hline & ERJ Open Research & RSS & Email: \\
\hline & European Respiratory & & journals@ersnet.org \\
\hline & Review & Subscriptions & \\
\hline Advertising & Breathe & & \\
\hline & ERS books online & Accessing the ERS & ISSN \\
\hline & ERS Bookshop & & Print ISSN: 0903-1936 \\
\hline & & & Online ISSN: $1399-3003$ \\
\hline & Help & & \\
\hline & Fee & & \\
\hline
\end{tabular}

Copyright $\odot 2020$ by the European Respiratory Society 